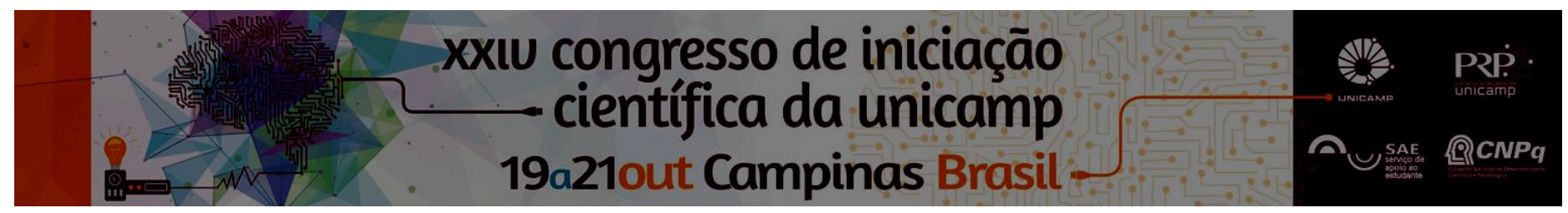

\title{
Efeito do uso de sistemas adesivos, armazenagem e cloridrato de doxiciclina na resistência de união à microtração na dentina
}

\author{
Laís M. Pinto (IC), Ana R. Costa (PQ), Eveline F. Soares (PG), Mário A.C. Sinhoreti (PQ), Américo B. Correr (PQ), \\ Lourenço Correr-Sobrinho (PQ)
}

\section{Resumo}

Este estudo avaliou a influência da aplicação do cloridrato de doxiciclina (DOX) nas concentrações de $3 \%$ e $10 \%$ na dentina humana através da resistência de união à microtração $(\mathrm{RU} \mu \mathrm{T})$, após 24 horas e 6 meses. A superfície oclusal de 60 terceiros molares humanos foi cortada, desgastada com lixas de granulação 600 e divididas em 6 grupos $(n=10): 1$ e 4 Controle (sem aplicação da DOX); 2 e 5 - aplicação da concentração de DOX 3\%; e, 3 e 6 - aplicação da concentração de DOX $10 \%$. A superfície da dentina foi condicionada com ácido fosfórico a $35 \%$ por $15 \mathrm{~s}$, lavado e seco. Em seguida, foi aplicada sobre a dentina a DOX 3\% e 10\%, por 5 minutos, o excesso foi removido deixando a dentina úmida e aplicado o adesivo Adper Scotchbond Multi-Purpose. Um bloco da resina composta Filtek Z250 foi construído sobre a superfície da dentina em três incrementos até atingir a altura de $5 \mathrm{~mm}$, sendo que cada incremento fotoativado por $20 \mathrm{~s}$ com o aparelho LED- Bluephase. Todas as amostras foram armazenadas em água deionizada a $37^{\circ} \mathrm{C}$ por 24 horas e seccionadas perpendicularmente à área de união, de modo a obter palitos com secção transversal de $1 \mathrm{~mm}^{2}$. Os palitos dos grupos 1

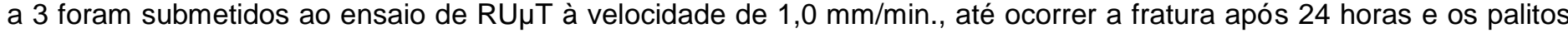
dos grupos 4 a 6, após 6 meses. Os dados foram submetidos à Análise de Variância dois fatores e ao teste de Tukey $(\alpha=$ $0,05)$. Os valores de RU $\mu \mathrm{T}(\mathrm{MPa})$ da doxiciclina $10 \% 46,7 \pm 2,1$ foi significativamente superior ao grupo controle $38,3 \pm 2,8$ $(p<0,05)$. Nenhuma diferença estatística foi observada entre a DOX $10 \%$ e $3 \% 42,4 \pm 2,4$, DOX $3 \%$ e grupo controle $(p>0,05)$. Os valores de RU $\mu \mathrm{T}$ para 24 horas $27,4 \pm 1,9$ foi estatisticamente superior a 6 meses $23,1 \pm 2,5(p<0,05)$. O uso da DOX $10 \%$ aumentou significativamente a $\mathrm{RU} \mu \mathrm{T}$ e a armazenagem reduziu a $\mathrm{RU} \mu \mathrm{T}$.

Palavras-chave: Doxiciclina, Sistema adesivo, Resistência de união.

\section{Introdução}

O sucesso clínico das restaurações cerâmicas depende do A doxiciclina (DOX) é um isómero de tetraciclina utilizadas como soluções desinfectantes na endodontia ou periodontais, por ser um antibiótico e com actividade quelante..$^{1-3} \mathrm{~A}$ deposição de resíduos de DOX ocorre na superfície da dentina, camada adesiva e híbrida promovendo alteração final nesta estrutura. Assim, o objetivo deste estudo foi avaliar a influência da aplicação da DOX nas concentrações de 3\% e 10\% na dentina humana através da resistência de união à microtração (RU $\mu T)$, após 24 horas e 6 meses.

\section{Resultados e Discussão}

Sessenta molares foram desgastados com lixas de granulação 600 e divididas em 6 grupos $(n=10)$ : 1 e 4 Controle (sem aplicação da DOX); 2 e 5 - aplicação da concentração de DOX 3\%; e, 3 e 6 - aplicação da concentração de DOX 10\%. Sobre a superfície da dentina foi aplicado a DOX $3 \%$ ou 10 , por 5 minutos, seguido do adesivo, resina composta Z250 $(5 \mathrm{~mm})$ e fotoativado por 60 $\mathrm{s}$. As amostras foram armazenadas em água deionizada a $37^{\circ} \mathrm{C}$ por 24 horas e obtidos palitos com $1 \mathrm{~mm}^{2}$. Os palitos dos grupos 1 a 3 foram submetidos ao ensaio de RU $R T$ à velocidade de $1,0 \mathrm{~mm} / \mathrm{min}$., após 24 horas e os palitos dos grupos 4 a 6 , após 6 meses. Os dados foram submetidos à Análise de Variância dois fatores e ao teste de Tukey $(\alpha=$ $0,05)$. Os valores de $R U \mu T(\mathrm{MPa})$ da doxiciclina $10 \%$ $46,7 \pm 2,1$ foi significativamente superior ao grupo controle $38,3 \pm 2,8 \quad(p<0,05)$. Nenhuma diferença estatística foi observada entre a DOX $10 \%$ e $3 \% 42,4 \pm 2,4$, DOX $3 \%$ e grupo controle $(p>0,05)$. Os valores de RU $\mu \mathrm{T}$ para 24 horas $27,4 \pm 1,9$ foi estatisticamente superior a 6 meses $23,1 \pm 2,5$ $(p<0,05)$

\section{Conclusão}

O uso da DOX $10 \%$ aumentou significativamente a RU $\mathrm{RT}$ e a armazenagem reduziu a $\mathrm{RU} \mu \mathrm{T}$.

\section{Agradecimentos}

Ao PIBIC/CNPq-PRP, pela bolsa de iniciação científica.

${ }^{1}$ Haznedaeroglu $\mathrm{F}$, Ersev $\mathrm{H}$. Tetracycline $\mathrm{HCl}$ solution as a root canal irrigant. $J$ Endod 2001; 27: 738-740.

${ }^{2}$ Torabinejad M, Khademi AA, Babagoli J, Cho Y, Johnson WB, Bozhilov K, Kim J, Shabahang S. A New Solution for the Removal Smear Layer. J Endod 2003; 29: 170-175.

${ }^{3}$ Deo V, Ansari S, Mandia S, Bhongade B. Therapeutic efficacy of subgingivally delivered doxycycline hyclate as an adjunct to non-surgical treatment of chronic periodontitis. $J$ Oral Maxillofac Res 2011; 2: e3. 